\title{
Climate Changing Impact on Water Resources
}

\author{
Msc. Rudina Uruci \\ "A. Xhuvani" University, Elbasan, Albania
}

\section{Doi:10.5901/mjss.2013.v4n10p644}

\section{Abstract}

Among the Social Consequences of Climate change, those affect and the hydrological cycle and water resources are expected to be serious. The analysis of the likely impacts of the Climate change for the Albanian coast reveals that drought, the. e. the prolongation of the low during dry periods - summer precipitation seasons, may be the most important directly consequence which, in turn, may lead to a cascade of secondary potentially harmful impacts, such as adequate quality drinking shortage of water. Decrease in the flow of surface waters, decrease in the recharge of aquifers, salt water intrusion due to sea level rise may cause coastal increased salinity in aquifers. This could create public health risks and increase the costs of water treatment and upset the ecology of the coastal area. In this study the present conditions as well as likely impacts as regards the hydrological and water resources are characteristics presented shortly,

\section{Introduction}

The global impact of climate change on the hydrological cycle with further consequences on water resources can have serious social and ecological consequences. When it comes to the impact on the hydrological cycle are considered changes in elements that interact within this cycle, the first rainfall, evaporation, infiltration and surface flow of moisture content in the soil. Water resources have an important role in social development, not only for the fact that the water used for drinking, but also for widespread use in Industry and agriculture.

However, it should be noted that it is very difficult to distinguish accurately the effects of climate changes in social economic effect of contrast, the human impact of climate change.

\section{Some hydrological features Hydrographic Network}

Water flow in the Albanian hydrographic watershed formed network and represents this potential watershed water discharges into the Mediterranean. The main rivers discharging into the Mediterranean (Adriatic) sea are: Drini, Buna, Mati, Shkumbini and Vjosa. Changes for a period of many years of wide vary within the limits (i.e. from $19.5109 \mathrm{~m} 3$ ) of dry years $(P=99 \%)$ at $73109 \mathrm{~m} 3$ for the wet $(P=1 \%)$

There are two characteristic periods in terms of water flow, wet period (October-May) and dry (June to September). Accordingly distribution is as follows:

$39 \%$ in the winter,

$33 \%$, in spring

$11 \%$ in summer

$17 \%$ in autumn

December and January register the highest values of flow, respectively 13.3 and $13.2 \%$ of the annual. They are followed by February (12.3\%), the month with the lowest water flow in different rivers and many years performance of total flow that flows into the Mediterranean Sea. Extinguished that 1963 is the most wet year $(Q=2.023$ m3sec- 1 ) while that of 1954 is most dry $(\mathrm{Q}=704 \mathrm{m3s}-1)$,

Is noted a reduction trend for the period 19852 - 1985, which is the lowest (8:15 m3s-1 to 24 years) in comparison with the total flow. Rainfall for the same period shows a similar trend with the flow. The lower is the amount of rainfall, the lower the flow. Thus, the effect of rainfall on water balance is explicit. Temperature also exerts its influence on water flow, but effect is implicit. Higher temperatures during the dry period are followed by a higher evaporation. Given that flow over the same period is lower evaporation or evapotranspiration currently are lower. During the wet period (October to May) the volume of flow is quite large, but given the low temperature of potential evapotranspiration is low.

\section{The Expected Climate Change}


As for next few years, from the application of general circulation models for Albania (UNEP, 1994) until year 2100 as a result of global climate warming changes are expected, which are expected to affect the hydrological cycle.

\subsection{Annual Scenario}

Can be expected a change of temperature from 0.7 to $2.5^{\circ} \mathrm{C}$, this means that the temperature limit above the annual average ranging between 17.2 and $20^{\circ} \mathrm{C}$, growing to be taken into consideration. However, in the annual rate is not expected any significant change in precipitation. According to a variation of the scenario expected average annual value of the amount of rainfall from 1000 to $2000 \mathrm{~mm}$ from the south to the north of the study area.

\subsection{Winter}

Increasing the temperature in winter is expected to attend the annual performance, while rainfall shows a decreasing trend $(-28$ to $+5 \%)$. This reduction may not be significant, since in winter rainfall recorded higher values than in other seasons $(330-730 \mathrm{~mm})$. As winter evaporation is low, such a reduction is expected to have a limited influence.

\subsection{Spring}

Temperature in this season is expected to change almost the same limits and annual temperature. Given that the average temperature in the study area varies between 13.8 and $15.7^{\circ} \mathrm{C}$, it is expected increase of $15.2-18.5^{\circ} \mathrm{C}$, while it is expected a very small increase in rainfall (up $0.18 \%$ )

\subsection{Summer}

According to the model, the average temperature this season is expected to range from 23.2 to $24.7^{\circ} \mathrm{C}$ for the study area, values that should be taken more into consideration. A serious impact on the hydrology of the area can be expected from the reduction of rainfall in the -22 to $-60 \%$ margins (currently in summer fall $13-63 \mathrm{~mm}$ rainfall).

\subsection{Autumn}

The temperature change is expected to be somewhat greater than the annual expected a "extended summer". The amount of rainfall in summer varies from 99 to $207 \mathrm{~mm}$, it is expected to grow $+53 \%$, an increase that will affect the hydrosphere.

According to climate change scenarios for the Albanian coast from are expected changes $+16 \mathrm{~cm}$ and $48 \mathrm{~cm}$ in the coast levels respectively for the years 2030 and 2100.

\section{Expected impacts of climate change}

All three elements of climate change (temperature rise, reducing of the rain flows and sea level rise) will affect the local water resources.

These changes can be mentioned as follows:

\subsection{Flow reduction of the surface water}

The analysis of rainfall scenarios show that the flow in the south is expected to decline more than $2 \%$ in 2030 and $5 \%$ in 2100. In the northern part of the country are not expected to change substantially the same time periods. It is important to note that the southern part of the country contains less than $20 \%$ of water resources, thus not expected to be any significant increase in flow.

4.2 Deterioration of water problem in general and drinking water in particular.

Possible reduction in summer rainfall is expected to exacerbate the problem of water in general, and increased precipitation during autumn and brought along his pollution growth is expected to exert a negative impact on vegetation 
and coastal ecosystems.

\subsection{In aquifers due to reduced precipitation, especially in summer.}

The latter, along with increased salinity as a result of penetration of sea salt water will lead to deterioration of the drinking water problem. It should be noted that the demand for potable water for social and economic needs are expected to grow. In line with the growth of population is estimated that the demand for potable water will be 280 million $\mathrm{m}^{3} / \mathrm{year}$ and what social and economic needs will vary from 655 to 850 million m³/year in the entire territory by 2025 (Blue Plan ). It is understood that these requirements will be much higher by 2100 .

\subsection{Increasing evapotranspiration throughout the year.}

Rising temperatures around $3^{\circ} \mathrm{C}$ can affect the growth of evapotranspiration on such a scale would lead to reduction of the total amount of water and save reduction and degradation of aquatic habitats. These problems can be seen especially in the summer, where it is expected a significant reduction of rainfall and less in the fall.

\subsection{Change the amount of sediment and coastal profile, as a result of increased intensity and frequency of flooding.}

\subsection{Increase the level of water in rivers and streams shoreline change.}

The penetrations of water into the seas are expected to be more pronounced in 2100 . It can be felt especially in post Mifoli (hydrometric station on the River Vjosa) $16 \mathrm{~cm}$ rise of sea levels are not expected to have any significant impact on groundwater. While the growth of $48 \mathrm{~cm}$ and reduction of the quantity of rainfall by 2100 is expected to cause increased water content of saline aquifers in the coastal zone.

As a result of the penetration of salt water of the sea is expected to increase groundwater salinity. This effect is expected to be more sensitive in the Fushe-Kuqe aquifer in the area of Durres, which had previously been expected to slough less felt in the field areas of Vlore \& Zadrima, due to greater heights above sea level (i.e. 1.67 and $1.83 \mathrm{~m}$ ). The same conclusion applies to all parts of the territory where the salty lands lie.

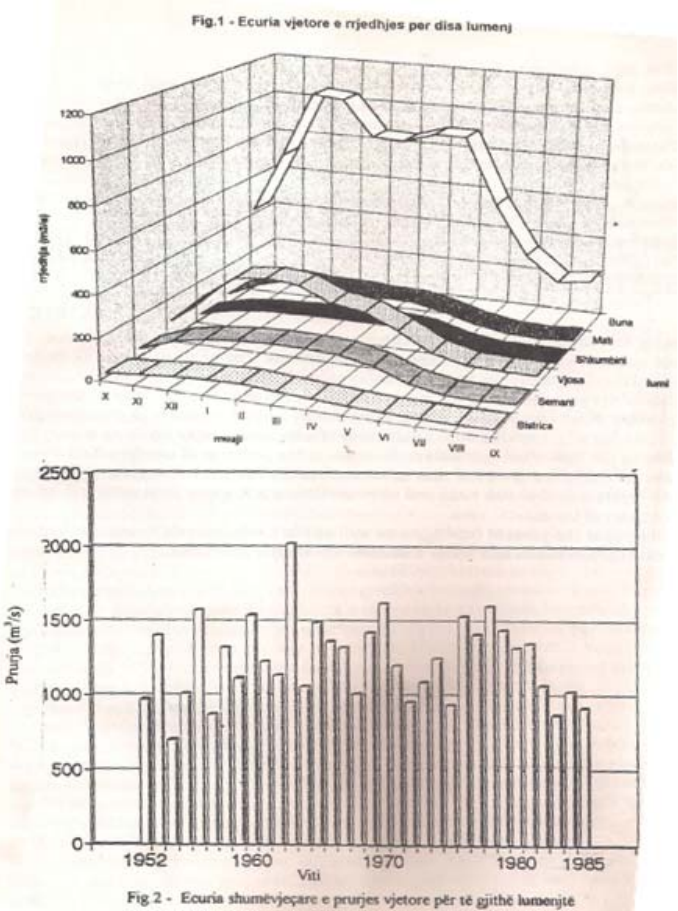

\section{Conclusions}

Fig 2 - Ecuria shumevjesare e prurjes vjetore per te githe lumenjte 
Changes in temperature and precipitation and sea level rise by 2030 are not expected to have any considerable impact on water resources.

For year 2100 results an extended drought periods in summer precipitation can be reduced most important direct consequences of the expected impacts. This, in turn, can contribute significantly to a cascade of other influences such as reducing the flow of surface water, deterioration of water problem in general and water in particular, reduction of reserves in aquifers. Sea level rise is the second factor that can influence in a series of negative impacts, among which we can mention the penetration of salt water into coastal aquifers, etc. shoreline erosion

\section{References}

HMI. 1984. Hydrology of Albania. Hidmet. Tirana

HMI. 1985. Climate and hydrological properties of Western Lowland Hidmet. Tirana

Jeftic, L; Micliman, I, D.; SESTINI, G. (eds) 1992: Climate change and the Mediterranean Edward Arnold. A division of Hodder and Stoughton. London. New York. Melbourne. Auefand

Palutikof, J, P.; Gou, X.; Wiggly, TML, Gregory, JM 1992: Regional Changes in climate in the Mediterranean Basis due to global greenhouse gas warming MAP Techmeal Reports Series N.66.UNEP.

Back,, N., 1984: The main features of water flow and the flow of solid Watershed hydrographic network of Albania. Meteorological Studies.

UNEP, 1994: Expected implications of Climate change on the English Coast UNEP (OCA / MEI) ËG.98 / 2. 